\title{
Strong convergence of a relaxed three-step iterative algorithm for countable families of pseudocontractions
}

\section{Wei-Qi Deng*}

\section{"Correspondence:}

dwq1273@126.com

College of Statistics and

Mathematics, Yunnan University of

Finance and Economics, Kunming,

Yunnan 650221, P.R. China

\begin{abstract}
An up-to-date method for the approximation of common fixed points of countable families of nonlinear operators is introduced, by which a relaxed three-step iterative algorithm is developed for the class of pseudocontractive mappings, and a strong convergence theorem is established in the framework of Hilbert spaces. Since there is no need to impose uniformity assumption on the involved Lipschitzian and closed mappings, the results improve and extend those announced by Cheng et al. (Fixed Point Theory Appl. 2013:100, 2013) and other authors with the related interest. MSC: $47 \mathrm{H} 05 ; 47 \mathrm{H} 09 ; 47 \mathrm{H} 10$

Keywords: Lipschitz pseudocontractions; common fixed points; countable families of nonlinear operators; strong convergence
\end{abstract}

\section{Introduction}

Let $C$ be a nonempty closed convex subset of a real Hilbert space $H$ with the inner product $\langle\cdot, \cdot\rangle$ and the corresponding norm $\|\cdot\|$. A mapping $T: C \rightarrow H$ is said to be nonexpansive if

$$
\|T x-T y\| \leq\|x-y\|, \quad \forall x, y \in C .
$$

A mapping $T: C \rightarrow H$ is called pseudocontractive or a pseudocontraction if

$$
\langle T x-T y, x-y\rangle \leq\|x-y\|^{2}, \quad \forall x, y \in C .
$$

Note that inequality (1.2) can be equivalently written as

$$
\|T x-T y\|^{2} \leq\|x-y\|^{2}+\|(I-T) x-(I-T) y\|^{2}, \quad \forall x, y \in C,
$$

where $I$ denotes the identity operator. A mapping $A$ with the domain $D(A)$ and the range $R(A)$ in $H$ is called monotone if the inequality

$$
\|x-y\| \leq\|(x-y)+s(A x-A y)\|
$$

holds for any $x, y \in D(A)$ and for all $s \geq 0$.

\section{Springer}

(c) 2013 Deng: licensee Springer. This is an Open Access article distributed under the terms of the Creative Commons Attribution License (http://creativecommons.org/licenses/by/2.0), which permits unrestricted use, distribution, and reproduction in any medium, provided the original work is properly cited. 
Not only from its being an important generalization of nonexpansive mappings, but also from the firm connection with the important class of nonlinear monotone mappings stems the interest in the class of pseudocontractions. We observe that $A$ is monotone if and only if $T:=I-A$ is pseudocontractive, and hence a zero $x^{*}$ of $A$, that is, $x^{*} \in \mathcal{N}(A):=$ $\{x \in D(A): A x=0\}$, is just a fixed point of $T$. It is well known (see, e.g., [1]) that if $A$ is monotone, then the solutions to the equation $A x=0$ correspond to the equilibrium points of some evolution systems. Considerable efforts have then been devoted to developing iterative techniques for approximating fixed points of pseudocontractive mappings (see, for example, [2-4] and the references contained therein).

In 2013, Cheng et al. [5] constructed the following three-step iteration method and obtain the convergence theorem for a countable family of Lipschitz pseudocontractive mappings in Hilbert space $H$. For the iteration format,

$$
\left\{\begin{array}{l}
x_{n+1}=\left(1-\alpha_{n}\right) x_{n}+\alpha_{n} T_{n} y_{n}, \\
y_{n}=\left(1-\beta_{n}\right) x_{n}+\beta_{n} T_{n} z_{n}, \\
z_{n}=\left(1-\gamma_{n}\right) x_{n}+\gamma_{n} T_{n} x_{n},
\end{array}\right.
$$

they proved that the sequence $\left\{x_{n}\right\}$ generated from above converges strongly to a common fixed point of $\left\{T_{n}\right\}_{n \geq 1}$. But it is worth mentioning that the involved mappings were assumed to be uniformly closed and uniformly Lipschitz pseudocontractive, which are obviously two quite strong conditions for countable families of nonlinear operators. Recall that a countable family of mapping $\left\{T_{n}\right\}_{n=1}^{\infty}: C \rightarrow H$ is called uniformly Lipschitz with Lipschitz constant $L_{n} \geq 0$, if there exists an $L:=\sup _{n \geq 1} L_{n}>0$ such that

$$
\left\|T_{n} x-T_{n} y\right\| \leq L\|x-y\|, \quad \forall x, y \in C, n \geq 1 .
$$

A countable family of mapping $\left\{T_{n}\right\}_{n=1}^{\infty}: C \rightarrow H$ is called uniformly closed if as $n \rightarrow \infty$, $x_{n} \rightarrow x^{*}$ and $\left\|x_{n}-T_{n} x_{n}\right\| \rightarrow 0$ imply $x^{*} \in \bigcap_{n=1}^{\infty} F\left(T_{n}\right)$.

Inspired and motivated by the studies mentioned above, in this paper, we introduced an up-to-date method for the approximation of common fixed points of countable families of nonlinear operators, by which a relaxed three-step iterative algorithm is developed for the class of pseudocontractive mappings, and a strong convergence theorem is established in the framework of Hilbert spaces. No compactness assumption is imposed either on the involved mappings or on the set $C$. The results are more applicable than those of other authors with the related interest.

\section{Preliminaries}

In the sequel, we shall need the following definitions. Let $H$ be a real Hilbert space. The function $\phi: H \times H \rightarrow \mathbb{R}$, defined by

$$
\phi(x, y):=\|x-y\|^{2}=\|x\|^{2}-2\langle x, y\rangle+\|y\|^{2},
$$

is studied by Alber [6], Kamimura and Takahashi [7] and Reich [8]. It is obvious from the definition of the function $\phi$ that

$$
(\|x\|-\|y\|)^{2} \leq \phi(x, y) \leq(\|x\|+\|y\|)^{2} .
$$


The function $\phi$ has also the following property

$$
\phi(y, x)=\phi(z, x)+\phi(y, z)+2\langle z-y, x-z\rangle .
$$

In what follows, we shall make use of the following lemmas.

Lemma 2.1 [9] Let $H$ be a Hilbert space. Then for all $x, y \in H$ and $\alpha_{i} \in[0,1]$ for $i=$ $0,1,2, \ldots, n$ such that $\sum_{i=0}^{n} \alpha_{i}=1$ the following equality holds

$$
\left\|\sum_{i=0}^{n} \alpha_{i} x_{i}\right\|^{2}=\sum_{i=0}^{n} \alpha_{i}\left\|x_{i}\right\|^{2}-\sum_{0 \leq i, j \leq n} \alpha_{i} \alpha_{j}\left\|x_{i}-x_{j}\right\|^{2}
$$

Lemma 2.2 [10] Let $\left\{a_{n}\right\},\left\{\delta_{n}\right\}$, and $\left\{b_{n}\right\}$ be the sequences of nonnegative real numbers satisfying

$$
a_{n+1} \leq\left(1+\delta_{n}\right) a_{n}+b_{n}, \quad \forall n \geq 1
$$

If $\sum_{n=1}^{\infty} \delta_{n}<\infty$ and $\sum_{n=1}^{\infty} b_{n}<\infty$, then $\lim _{n \rightarrow \infty} a_{n}$ exists.

Lemma 2.3 [11] The unique solutions to the positive integer equation

$$
n=i+\frac{(m-1) m}{2}, \quad m \geq i, n=1,2,3, \ldots
$$

are

$$
i=n-\frac{(m-1) m}{2}, \quad m=-\left[\frac{1}{2}-\sqrt{2 n+\frac{1}{4}}\right], n=1,2,3, \ldots
$$

where $[x]$ denotes the maximal integer that is not larger than $x$.

\section{Main results}

Recall that an operator $T$ on a Hilbert space is closed if $x_{n} \rightarrow x$ and $T x_{n} \rightarrow y$ as $n \rightarrow \infty$, then $T x=y$.

Theorem 3.1 Let $H$ be a real Hilbert space, and let $C$ be a closed convex nonempty subset of H. Let $\left\{T_{i}\right\}_{i=1}^{\infty}: C \rightarrow C$ be a sequence of closed and Lipschitz pseudocontractive mappings with Lipschitzian constants $L_{i}$ for each $i \geq 1$ and the interior of $F:=\bigcap_{i=1}^{\infty} F\left(T_{i}\right) \neq \emptyset$. Starting from an arbitrary $x_{1} \in C$, define $\left\{x_{n}\right\}$ by

$$
\left\{\begin{array}{l}
x_{n+1}=\left(1-\alpha_{i_{n}}\right) x_{n}+\alpha_{i_{n}} T_{i_{n}} y_{n} \\
y_{n}=\left(1-\beta_{i_{n}}\right) x_{n}+\beta_{i_{n}} T_{i_{n}} z_{n} \\
z_{n}=\left(1-\gamma_{i_{n}}\right) x_{n}+\gamma_{i_{n}} T_{i_{n}} x_{n}
\end{array}\right.
$$

where $\left\{\alpha_{i}\right\},\left\{\beta_{i}\right\},\left\{\gamma_{i}\right\} \subset(0,1)$ satisfying the following conditions: (i) $\alpha_{i} \leq \beta_{i} \leq \gamma_{i}$ and (ii) $\gamma_{i}^{3} L_{i}^{4}+2 \gamma_{i}^{2} L_{i}^{3}+\gamma_{i}^{2} L_{i}^{2}+\gamma_{i} L_{i}^{2}+2 \gamma_{i}<1$ for each $i \geq 1$; $i_{n}$ is the solutions to the positive 
integer equation: $n=i+\frac{(m-1) m}{2}(m \geq i, n=1,2, \ldots)$, that is, for each $n \geq 1$, there exists a unique $i_{n}$ such that

$$
\begin{aligned}
& i_{1}=1, \quad i_{2}=1, \quad i_{3}=2, \quad i_{4}=1, \quad i_{5}=2, \quad i_{6}=3, \\
& i_{7}=1, \quad i_{8}=2, \quad i_{9}=3, \quad i_{10}=4, \quad i_{11}=1,
\end{aligned}
$$

Then $\left\{x_{n}\right\}$ converges strongly to an $x^{*} \in F$.

Proof Let $p \in F$. Using the similar argument presented in the proof of [1, Theorem 3.1], we have from (3.1) and Lemma 2.1,

$$
\begin{aligned}
\left\|x_{n+1}-p\right\|^{2} \leq & \left(1-\alpha_{i_{n}}\right)\left\|x_{n}-p\right\|^{2}+\alpha_{i_{n}}\left\|y_{n}-p\right\|^{2}+\alpha_{i_{n}}\left\|y_{n}-T_{i_{n}} y_{n}\right\|^{2} \\
& -\alpha_{i_{n}}\left(1-\alpha_{i_{n}}\right)\left\|x_{n}-T_{i_{n}} y_{n}\right\|^{2}, \\
\left\|y_{n}-p\right\|^{2} \leq & \left(1-\beta_{i_{n}}\right)\left\|x_{n}-p\right\|^{2}+\beta_{i_{n}}\left\|z_{n}-p\right\|^{2}+\beta_{i_{n}}\left\|z_{n}-T_{i_{n}} z_{n}\right\|^{2} \\
& -\beta_{i_{n}}\left(1-\beta_{i_{n}}\right)\left\|x_{n}-T_{i_{n}} z_{n}\right\|^{2}
\end{aligned}
$$

and

$$
\begin{aligned}
\left\|z_{n}-p\right\|^{2} \leq & \left(1-\gamma_{i_{n}}\right)\left\|x_{n}-p\right\|^{2}+\gamma_{i_{n}}\left\|x_{n}-p\right\|^{2}+\gamma_{i_{n}}\left\|x_{n}-T_{i_{n}} x_{n}\right\|^{2} \\
& -\gamma_{i_{n}}\left(1-\gamma_{i_{n}}\right)\left\|x_{n}-T_{i_{n}} x_{n}\right\|^{2} \\
= & \left\|x_{n}-p\right\|^{2}+\gamma_{i_{n}}^{2}\left\|x_{n}-T_{i_{n}} x_{n}\right\|^{2} .
\end{aligned}
$$

In addition, from (3.1), we also have

$$
\begin{aligned}
\left\|z_{n}-T_{i_{n}} z_{n}\right\|^{2} \leq & \left(1-\gamma_{i_{n}}\right)\left\|x_{n}-T_{i_{n}} z_{n}\right\|^{2}+\gamma_{i_{n}} L_{i_{n}}^{2}\left\|x_{n}-z_{n}\right\|^{2} \\
& -\gamma_{i_{n}}\left(1-\gamma_{i_{n}}\right)\left\|x_{n}-T_{i_{n}} x_{n}\right\|^{2} \\
= & \left(1-\gamma_{i_{n}}\right)\left\|x_{n}-T_{i_{n}} z_{n}\right\|^{2} \\
& +\gamma_{i_{n}}\left(\gamma_{i_{n}}^{2} L_{i_{n}}^{2}+\gamma_{i_{n}}-1\right)\left\|x_{n}-T_{i_{n}} x_{n}\right\|^{2} .
\end{aligned}
$$

Substituting (3.4) and (3.5) into (3.3), we obtain that

$$
\begin{aligned}
\left\|y_{n}-p\right\|^{2} \leq & \left\|x_{n}-p\right\|^{2}+\beta_{i_{n}} \gamma_{i_{n}}\left(\gamma_{i_{n}}^{2} L_{i_{n}}^{2}+2 \gamma_{i_{n}}-1\right)\left\|x_{n}-T_{i_{n}} x_{n}\right\|^{2} \\
& +\beta_{i_{n}}\left(\beta_{i_{n}}-\gamma_{i_{n}}\right)\left\|x_{n}-T_{i_{n}} z_{n}\right\|^{2} .
\end{aligned}
$$

Since

$$
\begin{aligned}
\left\|y_{n}-T_{i_{n}} y_{n}\right\|^{2} \leq & \left(1-\beta_{i_{n}}\right)\left\|x_{n}-T_{i_{n}} y_{n}\right\|^{2}+\beta_{i_{n}} L_{i_{n}}^{2}\left\|z_{n}-y_{n}\right\|^{2} \\
& -\beta_{i_{n}}\left(1-\beta_{i_{n}}\right)\left\|x_{n}-T_{i_{n}} z_{n}\right\|^{2}
\end{aligned}
$$


and

$$
\begin{aligned}
\left\|z_{n}-y_{n}\right\| & \leq\left(\gamma_{i_{n}}-\beta_{i_{n}}\right)\left\|x_{n}-T_{i_{n}} x_{n}\right\|+\beta_{i_{n}} L_{i_{n}}\left\|x_{n}-z_{n}\right\| \\
& =\left(\gamma_{i_{n}}-\beta_{i_{n}}\right)\left\|x_{n}-T_{i_{n}} x_{n}\right\|+\beta_{i_{n}} \gamma_{i_{n}} L_{i_{n}}\left\|x_{n}-T_{i_{n}} x_{n}\right\| \\
& =\left(\gamma_{i_{n}}-\beta_{i_{n}}+\beta_{i_{n}} \gamma_{i_{n}} L_{i_{n}}\right)\left\|x_{n}-T_{i_{n}} x_{n}\right\|,
\end{aligned}
$$

it then follows from (3.7) and (3.8) that

$$
\begin{aligned}
\left\|y_{n}-T_{i_{n}} y_{n}\right\|^{2} \leq & \left(1-\beta_{i_{n}}\right)\left\|x_{n}-T_{i_{n}} y_{n}\right\|^{2} \\
& +\beta_{i_{n}} L_{i_{n}}^{2}\left(\gamma_{i_{n}}-\beta_{i_{n}}+\beta_{i_{n}} \gamma_{i_{n}} L_{i_{n}}\right)^{2}\left\|x_{n}-T_{i_{n}} x_{n}\right\|^{2} \\
& -\beta_{i_{n}}\left(1-\beta_{i_{n}}\right)\left\|x_{n}-T_{i_{n}} z_{n}\right\|^{2} .
\end{aligned}
$$

Substituting (3.6) and (3.9) into (3.2), we obtain that

$$
\begin{aligned}
\left\|x_{n+1}-p\right\|^{2} \leq & \left\|x_{n}-p\right\|^{2}+\left[\alpha_{i_{n}} \beta_{i_{n}} \gamma_{i_{n}}\left(\gamma_{i_{n}}^{2} L_{i_{n}}^{2}+2 \gamma_{i_{n}}-1\right)\right. \\
& \left.+\alpha_{i_{n}} \beta_{i_{n}} L_{i_{n}}^{2}\left(\gamma_{i_{n}}-\beta_{i_{n}}+\beta_{i_{n}} \gamma_{i_{n}} L_{i_{n}}\right)^{2}\right]\left\|x_{n}-T_{i_{n}} x_{n}\right\|^{2} \\
& +\alpha_{i_{n}}\left(\alpha_{i_{n}}-\beta_{i_{n}}\right)\left\|x_{n}-T_{i_{n}} y_{n}\right\|^{2} \\
& +\alpha_{i_{n}} \beta_{i_{n}}\left(2 \beta_{i_{n}}-\gamma_{i_{n}}-1\right)\left\|x_{n}-T_{i_{n}} z_{n}\right\|^{2},
\end{aligned}
$$

which, together with condition (i), that is, $\alpha_{i_{n}}\left(\alpha_{i_{n}}-\beta_{i_{n}}\right) \leq 0$ and $\alpha_{i_{n}} \beta_{i_{n}}\left(2 \beta_{i_{n}}-\gamma_{i_{n}}-1\right) \leq 0$, yields that

$$
\left\|x_{n+1}-p\right\|^{2} \leq\left\|x_{n}-p\right\|^{2}-\delta_{i_{n}}\left\|x_{n}-T_{i_{n}} x_{n}\right\|^{2}
$$

where $\delta_{i_{n}}:=\alpha_{i_{n}} \beta_{i_{n}} \gamma_{i_{n}}\left(1-\gamma_{i_{n}}^{2} L_{i_{n}}^{2}-2 \gamma_{i_{n}}\right)+\alpha_{i_{n}} \beta_{i_{n}} L_{i_{n}}^{2}\left(\beta_{i_{n}}-\gamma_{i_{n}}-\beta_{i_{n}} \gamma_{i_{n}} L_{i_{n}}\right)^{2}$. Noting that, in the light of condition (ii), $\delta_{i_{n}}>0$, we have

$$
\left\|x_{n+1}-p\right\| \leq\left\|x_{n}-p\right\| .
$$

So, by Lemma 2.2, we conclude that $\lim _{n \rightarrow \infty}\left\|x_{n}-p\right\|$ exists.

Furthermore, from (2.3), we also have that

$$
\phi\left(p, x_{n}\right)=\phi\left(x_{n+1}, x_{n}\right)+\phi\left(p, x_{n+1}\right)+2\left\langle x_{n+1}-p, x_{n}-x_{n+1}\right\rangle, \quad \forall p \in H .
$$

This implies that

$$
\left\langle x_{n+1}-p, x_{n}-x_{n+1}\right\rangle+\frac{1}{2} \phi\left(x_{n+1}, x_{n}\right)=\frac{1}{2}\left(\phi\left(p, x_{n}\right)-\phi\left(p, x_{n+1}\right)\right) .
$$

Moreover, since the interior of $F$ is nonempty, there exists a $p^{*} \in F$ and $r>0$ such that $\left(p^{*}+r h\right) \in F$ whenever $\|h\| \leq 1$. Thus, from (3.12) and (3.13), we obtain that

$$
0 \leq\left\langle x_{n+1}-\left(p^{*}+r h\right), x_{n}-x_{n+1}\right\rangle+\frac{1}{2} \phi\left(x_{n+1}, x_{n}\right) .
$$


Then from (3.13) and (3.14), we obtain that

$$
\begin{aligned}
r\left\langle h, x_{n}-x_{n+1}\right\rangle & \leq\left\langle x_{n+1}-p^{*}, x_{n}-x_{n+1}\right\rangle+\frac{1}{2} \phi\left(x_{n+1}, x_{n}\right) \\
& =\frac{1}{2}\left(\phi\left(p^{*}, x_{n}\right)-\phi\left(p^{*}, x_{n+1}\right)\right),
\end{aligned}
$$

and hence

$$
\left\langle h, x_{n}-x_{n+1}\right\rangle \leq \frac{1}{2 r}\left(\phi\left(p^{*}, x_{n}\right)-\phi\left(p^{*}, x_{n+1}\right)\right) .
$$

Since $h$ with $\|h\| \leq 1$ is arbitrary, we have

$$
\left\|x_{n}-x_{n+1}\right\| \leq \frac{1}{2 r}\left(\phi\left(p^{*}, x_{n}\right)-\phi\left(p^{*}, x_{n+1}\right)\right) .
$$

So, if $n>m$, then we have that

$$
\begin{aligned}
\left\|x_{m}-x_{n}\right\| & \leq \sum_{j=m}^{n-1}\left\|x_{j}-x_{j+1}\right\| \\
& \leq \frac{1}{2 r} \sum_{j=m}^{n-1}\left(\phi\left(p^{*}, x_{j}\right)-\phi\left(p^{*}, x_{j+1}\right)\right) \\
& =\frac{1}{2 r}\left(\phi\left(p^{*}, x_{m}\right)-\phi\left(p^{*}, x_{n}\right)\right) .
\end{aligned}
$$

Since $\left\{\phi\left(p^{*}, x_{n}\right)\right\}$ converges, it then follows from (3.15) that $\left\{x_{n}\right\}$ is a Cauchy sequence, and hence there exists an $x^{*} \in H$ such that

$$
x_{n} \rightarrow x^{*} \in H \quad(n \rightarrow \infty) .
$$

Next, set $\mathbb{N}_{i}=\left\{k \in \mathbb{N}: k=i+\frac{(m-1) m}{2}, m \geq i, m \in \mathbb{N}\right\}$ for each $i \geq 1$. For example, by Lemma 2.3 and the definition of $\mathbb{N}_{1}$, we have $\mathbb{N}_{1}=\{1,2,4,7,11,16, \ldots\}$ and $i_{1}=i_{2}=i_{4}=$ $i_{7}=i_{11}=i_{16}=\cdots=1$. Note that $T_{i_{k}}=T_{i}, \delta_{i_{k}}=\delta_{i}$ whenever $k \in \mathbb{N}_{i}$ for each $i \geq 1$. We have, from (3.11),

$$
\delta_{i}\left\|x_{k}-T_{i} x_{k}\right\|^{2} \leq\left\|x_{k}-p\right\|^{2}-\left\|x_{k+1}-p\right\|^{2}, \quad \forall k \in \mathbb{N}_{i} .
$$

Since $\left\{x_{k}\right\}_{k \in \mathbb{N}_{i}}$ and $\left\{x_{k+1}\right\}_{k \in \mathbb{N}_{i}}$ are subsequences of $\left\{x_{n}\right\}$, the existence of $\lim _{n \rightarrow \infty}\left\|x_{n}-p\right\|$ implies that

$$
\lim _{\mathbb{N}_{i} \ni k \rightarrow \infty}\left\|x_{k}-T_{i} x_{k}\right\|=0, \quad \forall i \geq 1
$$

Note that, from (3.16), $x_{k} \rightarrow x^{*}$ as $\mathbb{N}_{i} \ni k \rightarrow \infty$. It immediately follows from (3.18) and the closedness of $T_{i}$ that $x^{*} \in F\left(T_{i}\right)$ for each $i \geq 1$, and hence $x^{*} \in F$. This completes the proof.

We now give an example, to which the results of Cheng et al. [5] cannot be applied. 
Example 3.2 Let $H=\mathbb{R}^{1}$ and $C=[-1,1]$. Let $\left\{T_{i}\right\}_{i=1}^{\infty}: C \rightarrow C$ be a sequence of nonlinear mappings defined by

$$
T_{i} x= \begin{cases}\left(\frac{i}{2 i+1}+\frac{1}{2}\right) x, & x \in C_{1}:=[0,1], \\ x, & x \in C_{2}:=[-1,0) .\end{cases}
$$

It is clear that $F:=\bigcap_{i=1}^{\infty} F\left(T_{i}\right)=[-1,0]$, and hence the interior of the common fixed points is nonempty. We show that $\left\{T_{i}\right\}_{i=1}^{\infty}$ is a countable family of pseudocontractive mappings. If $x \in C_{2}$ and $y \in C_{1}$, then

$$
\begin{aligned}
\left\langle T_{i} x-T_{i} y, x-y\right\rangle & =\left\langle x-\left(\frac{i}{2 i+1}+\frac{1}{2}\right) y, x-y\right\rangle \\
& =\left\langle(x-y)+\left(\frac{1}{2}-\frac{i}{2 i+1}\right) y, x-y\right\rangle \\
& =|x-y|^{2}-\left(\frac{i}{2 i+1}-\frac{1}{2}\right)(x-y) y .
\end{aligned}
$$

Noting that $\left(\frac{i}{2 i+1}-\frac{1}{2}\right)(x-y) y>0$, we have

$$
\left\langle T_{i} x-T_{i} y, x-y\right\rangle \leq|x-y|^{2} .
$$

The rest is trivial, and it is easy to show that each $T_{i}$ is Lipschitz and closed. However, $\left\{T_{i}\right\}_{i=1}^{\infty}$ is not uniformly closed. In fact, for any $[0,1] \supset\left\{x_{i}\right\} \rightarrow x^{*} \in(0,1]$ as $i \rightarrow \infty$, we have

$$
\left|x_{i}-T_{i} x_{i}\right|=\left|x_{i}-\left(\frac{i}{2 i+1}+\frac{1}{2}\right) x_{i}\right| \rightarrow 0 \quad(i \rightarrow \infty),
$$

while $x^{*}$ is obviously not a member of $F$.

Remark 3.3 By using a specific way of choosing the indexes of the involved mappings and parameters, we propose an up-to-date iterative approach to approximating common fixed points of countable families of pseudocontractive mappings. The results extend previous results, announced by the authors with the related research interest.

\section{Competing interests}

The author declares that they have no competing interests.

\section{Acknowledgements}

The author is very grateful to the referees for their useful suggestions, by which the contents of this article has been improved. This work is supported by the National Natural Science Foundation of China (Grant No. 11061037).

Received: 29 April 2013 Accepted: 29 July 2013 Published: 14 August 2013

\section{References}

1. Zeidler, E: Nonlinear Functional Analysis and Its Applications, Part II: Monotone Operators. Springer, Berlin (1985)

2. Chidume, CE, Moore, C: The solution by iteration of nonlinear equations in uniformly smooth Banach spaces. J. Math. Anal. Appl. 215, 132-146 (1997)

3. Liu, Q: The convergence theorems of the sequence of Ishikawa iterates for hemi-con tractive mappings. J. Math. Anal. Appl. 148, 55-62 (1990)

4. Zhang, S: On the convergence problems of Ishikawa and Mann iteration processes with error for $\phi$-pseudocontractive type mappings. Appl. Math. Mech. 21, 1-10 (2000) 
5. Cheng, Q, Su, Y, Zhang, J: Convergence theorems of a three-step iteration method for pseudocontractive mappings. Fixed Point Theory Appl. 2013, 100 (2013). doi:10.1186/1687-1812-2013-100

6. Alber, Yl: Metric and generalized projection operators in Banach spaces: properties and applications. In: Kartsatos, AG (ed.) Theory and Applications of Nonlinear Operators of Accretive and Monotone Type. Lecture Notes in Pure and Appl. Math., vol. 178, pp. 15-50. Dekker, New York (1996)

7. Kamimura, S, Takahashi, W: Strong convergence of proximal-type algorithm in a Banach space. SIAM J. Optim. 13, 938-945 (2002)

8. Reich, S: A weak convergence theorem for the alternating method with Bergman distance. In: Kartsatos, AG (ed.) Theory and Applications of Nonlinear Operators of Accretive and Monotone Type. Lecture Notes in Pure and Appl. Math., vol. 178, pp. 313-318. Dekker, New York (1996)

9. Zegeye, H, Shahzad, N: Convergence of Mann's type iteration method for generalized asymptotically nonexpansive mappings. Comput. Math. Appl. 62, 4007-4014 (2011)

10. Osilike, MO, Aniagbosor, SC, Akuchu, BG: Fixed points of asymptotically demicontractive mappings in arbitrary Banach spaces. Panam. Math. J. 12, 77-88 (2002)

11. Deng, WQ, Bai, $P$ : An implicit iteration process for common fixed points of two infinite families of asymptotically nonexpansive mappings in Banach spaces. J. Appl. Math. 2013, Article ID 602582 (2013)

doi:10.1186/1687-1812-2013-217

Cite this article as: Deng: Strong convergence of a relaxed three-step iterative algorithm for countable families of pseudocontractions. Fixed Point Theory and Applications 2013 2013:217.

\section{Submit your manuscript to a SpringerOpen ${ }^{\circ}$ journal and benefit from:}

- Convenient online submission

Rigorous peer review

- Immediate publication on acceptance

Open access: articles freely available online

- High visibility within the field

- Retaining the copyright to your article 